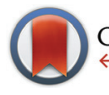

CrossMark \&click for updates

Cite this: Dalton Trans., 2016, 45 14538

Received 9th May 2016,

Accepted 11th July 2016

DOI: $10.1039 / c 6 d t 01815 g$

www.rsc.org/dalton

\section{A cobalt(II) iminoiodane complex and its scandium adduct: mechanistic promiscuity in hydrogen atom abstraction reactions $\uparrow$}

\author{
Subrata Kundu, ${ }^{a}$ Petko Chernev, ${ }^{\mathrm{b}}$ Xenia Engelmann, ${ }^{\mathrm{a}}$ Chan Siu Chung, ${ }^{\mathrm{c}}$ Holger Dau, ${ }^{\mathrm{b}}$ \\ Eckhard Bill, ${ }^{d}$ Jason England, ${ }^{* \mathrm{c}}$ Wonwoo Nam* ${ }^{* \mathrm{e}}$ and Kallol Ray ${ }^{* a}$
}

In addition to oxometal $\left[\mathrm{M}^{n+}=\mathrm{O}\right]$ and imidometal $\left[\mathrm{M}^{n+}=\mathrm{NR}\right]$ units, transient metal-iodosylarene $\left[\mathrm{M}^{(n-2)+}-\mathrm{O}=\mathrm{IPh}\right]$ and metaliminoiodane $\left[\mathrm{M}^{(n-2)+}-\mathrm{N}(\mathrm{R})=\mathrm{IPh}\right]$ adducts are often invoked as a possible "second oxidant" responsible for the oxo and imido group transfer reactivity. Although a few metal-iodosylarene adducts have been recently isolated and/or spectroscopically characterized, metal-iminoiodane adducts have remained elusive. Herein, we provide UV-Vis, EPR, NMR, XAS and DFT evidence supporting the formation of a metal-iminoiodane complex 2 and its scandium adduct 2-Sc. 2 and 2-Sc are reactive toward substrates in the hydrogen-atom and nitrene transfer reactions, which confirm their potential as active oxidants in metal-catalyzed oxidative transformations. Oxidation of para-substituted 2,6-di-tert-butylphenols by 2 and 2-Sc can occur by both coupled and uncoupled proton and electron transfer mechanisms; the exact mechanism depends on the nature of the para substituent.

Iodosobenzene $(\mathrm{PhI}=\mathrm{O})$ and iminoiodanes $(\mathrm{PhI}=\mathrm{NR})$ are an important class of group transfer reagents in organic synthesis, and they are often used in conjunction with transition metal-based catalysts. ${ }^{1}$ High-valent oxometal $\left[\mathrm{M}^{n+}=\mathrm{O}\right]$ and imidometal $\left[\mathrm{M}^{n+}=\mathrm{NR}\right]$ units are generally accepted to be key reactive intermediates in these reactions. ${ }^{2}$ However, transient metal-iodosylarene $\left[\mathrm{M}^{(n-2)+}-\mathrm{O}=\mathrm{IPh}\right]^{3}$ and metal-iminoiodane $\left[\mathrm{M}^{(n-2)+}-\mathrm{N}(\mathrm{R})=\mathrm{IPh}\right]^{4}$ adducts have also been suggested as a possible "second oxidant" responsible for this oxo and imido

${ }^{a}$ Humboldt-Universität zu Berlin, Institut für Chemie, Brook-Taylor-Straße 2, D-12489 Berlin, Germany. E-mail: kallol.ray@chemie.hu-berlin.de; Fax: +49302093 7387; Tel: +493020937385

${ }^{b}$ Freie Universität Berlin, FB Physik, Arnimallee 14, D-14195-Berlin, Germany ${ }^{c}$ Division of Chemistry and Biological Chemistry, School of Physical and Mathematical Sciences, Nanyang Technological University, 21 Nanyang Link, Singapore 637371. E-mail: jengland@ntu.edu.sg

${ }^{d}$ Max-Plank-Institut für Chemische Energiekonversion, Stiftstraße 34-36, D-45470 Mülheim an der Ruhr, Germany

${ }^{e}$ Department of Chemistry and Nano Science, Center for Biomimetic System, Ewha Womans University, Seoul 120-750, Korea.E-mail: wwnam@ewha.ac.kr $\dagger$ Electronic supplementary information (ESI) available. See DOI: 10.1039/c6dt01815g group transfer reactivity. Nam et al. reported the first isolation and spectroscopic characterization of an iodosobenzene adduct, namely $\left[(\text { porph }) \mathrm{Fe}^{\mathrm{III}}(\mathrm{OIPh})\right]^{+}$, from the reaction of $\left[\left(\text { porph }^{+\bullet}\right) \mathrm{Fe}^{\mathrm{IV}} \mathrm{O}\right]^{+}$with iodobenzene. ${ }^{3 c}$ Very recently, McKenzie et al. provided the molecular structure of a non-heme iron(III) iodosylarene adduct by X-ray crystallography. ${ }^{3 d}$ Fujii et $a .^{3 e, f}$ also reported structural and spectroscopic evidence in support of bis(iodosylarene) coordination to a manganese(Iv)-salen center. Notably, the aforementioned isolated $\left[\mathrm{M}^{(n-2)+}-\mathrm{O}=\mathrm{IPh}\right]$ adducts were all found to be reactive toward substrates in both hydrogen- and oxygen-atom transfer reactions, which confirms their potential as active oxidants in metal-catalyzed oxidative transformations. ${ }^{3}$ In contrast, isoelectronic $\left[\mathrm{M}^{(n-2)+}-\mathrm{N}(\mathrm{R})=\mathrm{IPh}\right]$ complexes have remained elusive, and their presence as transient reactive intermediates has been forwarded on the basis of labelling experiments alone. ${ }^{4 a}$

Herein, we describe the spectroscopic characterization of a novel $\left[\left(\mathrm{TMG}_{3} \text { tren }\right) \mathrm{Co}^{\mathrm{II}}-\left({ }^{\mathrm{S}} \mathrm{PhINTs}\right)\right]^{2+}$ (2) complex $\left[{ }^{\mathrm{S}} \mathrm{PhINTs}=\right.$ $\{N$-( $p$-toluenesulfonyl)imino $\}$ (2-tert-butylsulfonyl)phenyliodinane; ${ }^{5}$ $\mathrm{TMG}_{3}$ tren $=\operatorname{tris}[2-\{N$-tetramethylguanidyl $\}$ ethyl $]$ amine $]$ and its scandium adduct $\left[\left(\mathrm{TMG}_{3} \text { tren }\right) \mathrm{Co}^{\mathrm{II}}-{ }^{\mathrm{s}} \mathrm{PhINTs}\left(\mathrm{Sc}(\mathrm{OTf})_{3}\right)\right]^{2+}(2-\mathrm{Sc}$, OTf $=\mathrm{CF}_{3} \mathrm{SO}_{2}{ }^{-}$), which are able to oxidize the $\mathrm{C}-\mathrm{H}$ and $\mathrm{O}-\mathrm{H}$ bonds of a variety of substrates. Additionally, we demonstrate that the presence of $\mathrm{Sc}^{3+}$ in 2-Sc initiates a two-step reaction mechanism for the oxidation of benzyl alcohol $\left(\mathrm{PhCH}_{2} \mathrm{OH}\right)$, involving a $\left[\mathrm{Co}^{\mathrm{II}}-\left({ }^{\mathrm{S}} \mathrm{PhINTs}\right) \cdots \mathrm{Sc}^{3+} \ldots \mathrm{O}(\mathrm{H})-\mathrm{CH}_{2} \mathrm{Ph}\right]$ association event prior to $\mathrm{C}-\mathrm{H}$ bond cleavage. In the case of para-substituted phenols two different mechanistic pathways have been established for reactions with 2 and 2-Sc: a concerted protoncoupled electron transfer (PCET), and a proton transfer followed by electron transfer (PT-ET). The nature of the phenol para-substituent is shown to control the mechanism of oxidation.

A combination of $\left[\left(\mathrm{TMG}_{3} \text { tren }\right) \mathrm{Co}^{\mathrm{II}}-\mathrm{OTf}\right]^{+}$(1) with ${ }^{\mathrm{s}} \mathrm{PhINTs}^{5}$ in acetone at $-40^{\circ} \mathrm{C}$ led after 6000 seconds to the formation of an orange complex 2 with absorption maxima $\lambda_{\max }\left[\varepsilon_{\max }\right]$ centered at $420 \mathrm{~nm}\left[1150 \mathrm{M}^{-1} \mathrm{~cm}^{-1}\right]$ and $820 \mathrm{~nm}\left[130 \mathrm{M}^{-1} \mathrm{~cm}^{-1}\right]$ (Fig. S1 ${ }^{\dagger}$ ). The absorption spectrum of 2 is clearly distinct from $1+{ }^{\mathrm{s}} \mathrm{PhINTs}$ (Fig. 1), and titration experiments (Fig. 1 


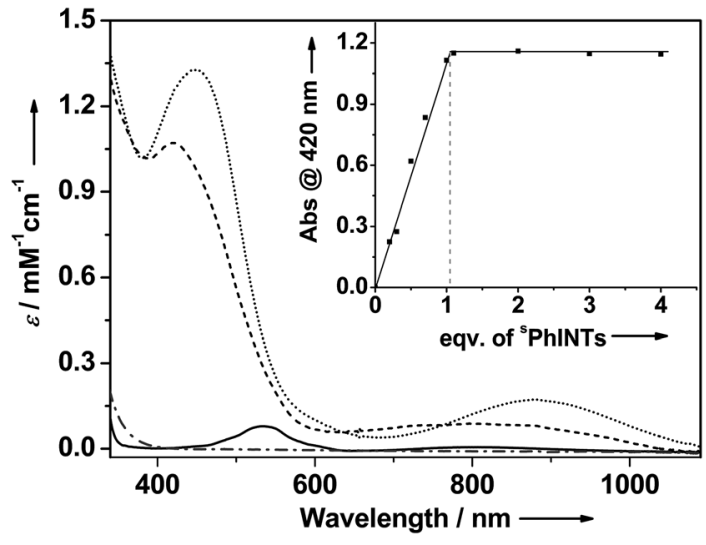

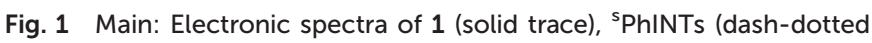
trace), 2 (dashed trace), and 2-Sc (dotted trace) in acetone at $-40{ }^{\circ} \mathrm{C}$. Inset: Plot of the absorbance of the $420 \mathrm{~nm}$ band of 2 against the equivalents of ${ }^{\mathrm{S}} \mathrm{PhINTs}$ added to 1 . Notably, 2 and 2 -Sc can also be generated in $\mathrm{CH}_{2} \mathrm{Cl}_{2}$ with $\lambda_{\max }$ [ $\left.\varepsilon_{\text {max }}\right]$ values identical to that observed in acetone.

inset) show that addition of only 1 equiv. ${ }^{\text {s }}$ PhINTs to $\mathbf{1}$ is necessary to maximize the yield of 2 . Similarly, the ${ }^{1} \mathrm{H}-\mathrm{NMR}$ spectrum of $\mathbf{2}$ is distinct from that of $\mathbf{1}+$ free ${ }^{\mathrm{S}}$ PhINTs (Fig. S2 and $\mathrm{S} 3 \uparrow$ ), and does not show the presence of any unreacted starting materials in significant amounts. Moreover, in the ${ }^{1} \mathrm{H}$-NMR spectrum of 2 the complete set of signals expected for ${ }^{\mathrm{s}}$ PhINTs are observed (Fig. S3 $\dagger$ ), which are broadened and shifted to slightly higher fields relative to free ${ }^{\mathrm{s}} \mathrm{PhINTs}$; this can be attributed to binding to the paramagnetic cobalt centre.

Upon addition of scandium triflate $\left(\mathrm{Sc}(\mathrm{OTf})_{3}\right)$ at $-40{ }^{\circ} \mathrm{C}, 2$ is instantaneously converted to a new species 2-Sc $\left(\lambda_{\max }\left[\varepsilon_{\max }\right]\right.$ $=450 \mathrm{~nm}\left[1350 \mathrm{M}^{-1} \mathrm{~cm}^{-1}\right]$ and $\left.885 \mathrm{~nm}\left[180 \mathrm{M}^{-1} \mathrm{~cm}^{-1}\right]\right)$ (Fig. 1). As was the case for ${ }^{\mathrm{s}} \mathrm{PhINTs}$, only 1 equiv. $\mathrm{Sc}^{3+}$ is required for complete conversion of 2 to 2 -Sc (Fig. S4 $\dagger$ ). Notably, complex 1 can also be converted directly to 2 -Sc by reacting with ${ }^{\mathrm{S}} \mathrm{PhINTs}$ in the presence of 1 equiv. $\mathrm{Sc}(\mathrm{OTf})_{3}$. Both 2 and 2-Sc are meta-stable intermediates with half-lives $\left(t_{1 / 2}\right)$ of 3600 and 720 seconds, respectively, at $25^{\circ} \mathrm{C}$.

The electronic structures of 2 and 2-Sc were probed by EPR spectroscopy. Surprisingly, in spite of the significant differences in their UV-Vis spectra, the X-band EPR spectra of 2 and 2-Sc (Fig. S5 $\dagger$ ) exhibit identical axial $S=3 / 2$ signals, with effective $g$ values of $g^{\perp}=4.40$ and $g^{\|}=2.09$ that are strikingly similar to the previously reported ${ }^{6}$ axial EPR signals of $\mathbf{1}$. Furthermore, the EPR spectra of the series of $\left[\left(\mathrm{TMG}_{3} \text { tren }\right) \mathrm{Co}^{\mathrm{II}} \mathrm{X}\right]^{+}$ $\left(\mathrm{X}=\mathrm{OTf}, \mathrm{Cl}, \mathrm{SCN}, \mathrm{N}_{3}, \mathrm{CH}_{3} \mathrm{COO}, \mathrm{CN}\right)$ complexes all exhibit axial $S=3 / 2$ signals identical to 2 , with effective $g$ values of $g^{\perp}=4.40$ and $g^{\|}=2.09$, even though their UV-Vis spectra are distinct from one another (Fig. S6 $\dagger$ ). This shows that the EPR parameters of the $\left\{\left(\mathrm{TMG}_{3}\right.\right.$ tren $\left.) \mathrm{Co}^{\mathrm{II}}\right\}$ moiety are effectively independent of the nature of the fifth ligand, and appear to be dictated solely by the strong binding of the $\mathrm{TMG}_{3}$ tren ligand to the $\mathrm{Co}^{\mathrm{II}}$ ion. The EPR parameters change only when the formal oxidation state of cobalt is altered. For example, a rhombic EPR spectrum $(E / D=0.15 \pm 0.01)$ with split effective $g^{\perp}=5.60,3.60$, and $g^{\|}=1.96$ was observed for the unusual $\left\{\left(\mathrm{TMG}_{3}\right.\right.$ tren $\left.) \mathrm{Co}^{\mathrm{IV}}-\mathrm{O}-\mathrm{Sc}^{3+}\right\}$ (3-Sc) core containing a cobalt center with a formal oxidation state of $+4 .{ }^{6}$ Taken together, the nearidentical EPR spectra of 2, 2-Sc, and $\mathbf{1}$ indicate that the cobalt centers in $\mathbf{2}$ and 2-Sc retain the +2 oxidation state of $\mathbf{1}$.

2 and 2-Sc were further characterized by X-ray absorption spectroscopy (XAS). The positions of the Co K-edges of these complexes do not differ from that of $\mathbf{1}$ (Fig. S7 $\dagger$ ), which indicates that the reaction of $\mathbf{1}$ with ${ }^{\mathrm{s}} \mathrm{PhINTs}$ does not cause a change in the $\mathrm{Co}^{\mathrm{II}}$ oxidation state. This result is in agreement with our EPR study and is in stark contrast to 3 -Sc, ${ }^{6}$ whose Co K-edge energy was found to be blue-shifted by $1.3 \mathrm{eV}$ relative to 1 .

The principal feature of the inner-sphere scattering peaks in the extended X-ray absorption fine structure (EXAFS) spectra of 2 and 2-Sc (Fig. 2, S8 and Table S1†) at $R^{\prime} \sim 1.67 \AA$ (similar to that previously reported for $\mathbf{1})^{6}$ can be fitted in both cases with a single shell of $5 \mathrm{O} / \mathrm{N}$ scatterers at a distance of $\sim 2.05 \AA$, and corresponds to the donor atoms of $\mathrm{TMG}_{3}$ tren and ${ }^{5}$ PhINTs. Notably, in contrast to $\mathbf{3}-\mathbf{S c},{ }^{6}$ no evidence of a short Co-N/O distance could be obtained from the fit of the EXAFS data of either 2 or 2-Sc. The outer-shell features in the EXAFS spectra of $\mathbf{2}$ and 2-Sc can be satisfactorily accounted for by considering single scattering paths involving $8 \mathrm{C}$ atoms at 2.9-3.0 $\AA$ and $6 \mathrm{C} / \mathrm{N}$ atoms at 3.4-3.5 $\AA$. Satisfactory fitting of the EXAFS data of 2 requires inclusion of an additional outershell scatterer at $3.78 \AA$ corresponding to a single sulfur or iodine atom (fits 4 and 5 in Table S2†). The removal of this shell significantly lowers the quality of the fit (fit 3 in Table S2 $\dagger$ ). The best fit of the EXAFS data of 2-Sc (fit 8 in Table S3 $\uparrow$ ) requires an outer-shell scatterer at $3.62 \AA$, which can be assigned to a Sc atom, in addition to the Co-S scatterer at $3.66 \AA$.

Taken together, the XAS, EPR, NMR, and UV-Vis data of $\mathbf{1}, 2$ and 2-Sc conclusively indicate that a $\mathrm{Co}^{\mathrm{II}}$ oxidation state is retained throughout this series. Complex 2 is, therefore, formulated as the five-coordinate cobalt(II)-iminoiodane adduct $\left[\left(\mathrm{TMG}_{3} \text { tren }\right) \mathrm{Co}^{\mathrm{II}}-\left({ }^{\mathrm{S}} \mathrm{PhINTs}\right)\right]^{2+}$ (Scheme 1), and 2-Sc is proposed to be $\left[\left(\mathrm{TMG}_{3} \text { tren }\right) \mathrm{Co}^{\mathrm{II}}-\left({ }^{\mathrm{S}} \mathrm{PhINTs}\right)\left(\mathrm{Sc}(\mathrm{OTf})_{3}\right)\right]^{2+}$, wherein a single $\mathrm{Sc}^{3+}$ ion binds directly to the $\left[\left(\mathrm{TMG}_{3} \text { tren }\right) \mathrm{Co}^{\mathrm{II}}-\left({ }^{\mathrm{S}} \mathrm{PhINTs}\right)\right]^{2+}$ complex. ${ }^{8}$ Consistent with this assignment the electrospray
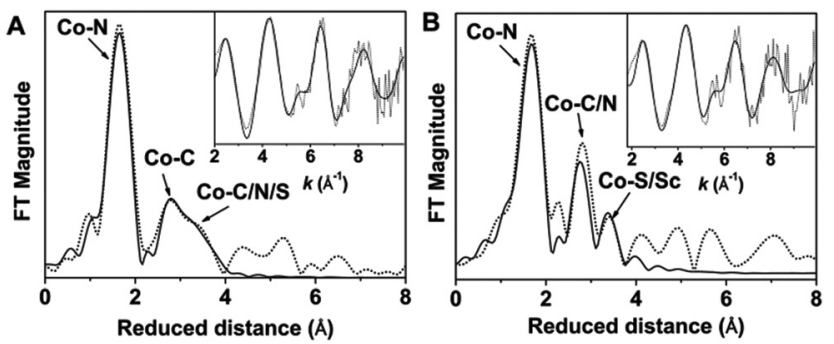

Fig. 2 Fourier-transformed Co K-edge EXAFS spectra of 2 (A) and 2-Sc (B) [experimental data: dotted line, simulation: solid line]. Insets show the corresponding EXAFS data in a wave-vector scale before the Fourier transformations. 


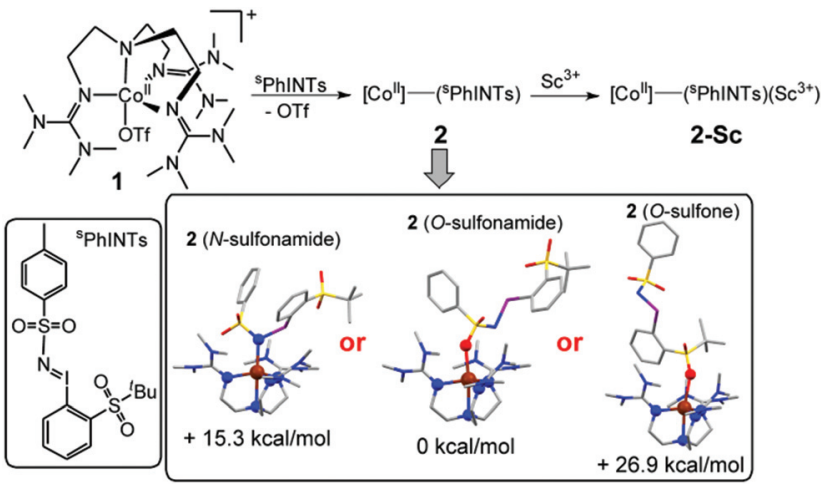

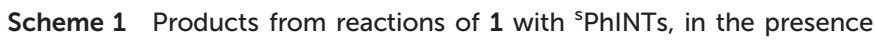
and absence of $\mathrm{Sc}^{3+}$ ions. The DFT calculated possible structures of 2 and their relative energies in the $S=3 / 2$ ground state are shown in the inset. Color code: C, grey; O, red; N, blue; Co, brown; sulfur, yellow; iodine, violet.

mass spectrum (ESI-MS; Fig. S9†) of both 2 and 2-Sc exhibits a prominent peak at $m / z=496.15$, with a mass and isotope distribution pattern corresponding to $\left[\left(\mathrm{TMG}_{3} \text { tren }\right) \mathrm{Co}^{\mathrm{II}}-\left({ }^{\mathrm{S}} \mathrm{PhINTs}\right)\right]^{2+}$.

DFT calculations were also performed in order to obtain further insights into the electronic and geometric structures of 2 . $^{7}$ The binding of ${ }^{5}$ PhINTs to the cobalt center in 2 can in principle occur either via the sulfonamide group (O-bound or $\mathrm{N}$-bound) or alternatively via one of the O-atoms of the sulfone group (Scheme 1 and Table S4 $\dagger$ ). The most stable structure of the experimentally observed spin-quartet ground $(S=3 / 2)$ state was calculated to contain the O-bound sulfonamide binding mode of ${ }^{\mathrm{S}}$ PhINTs (Scheme 1, inset), with the respective energies (Table S5 $\dagger$ ) of the geometry optimized structures of the more sterically disfavoured N-bound sulfonamide and O-bound sulfone isomers being higher by 15.3 and 26.9 kcal $\mathrm{mol}^{-1}$ respectively. Consistent with this conclusion, the DFT calculated average Co-N/O distance of $2.10 \AA$ (corresponding to four N-donors of $\mathrm{TMG}_{3}$ tren and one O-donor of ${ }^{\mathrm{S}} \mathrm{PhINTs}$ ) in an $S=3 / 2$ O-bound sulfonamide $\left[\left(\mathrm{TMG}_{3} \text { tren }\right) \mathrm{Co}^{\mathrm{II}}-\left({ }^{\mathrm{S}} \mathrm{PhINTs}\right)\right]^{2+}$ complex (Tables S1 and $\mathrm{S} 4 \dagger$ ) best matches the EXAFS determined Co-N/O distance of $2.05 \AA$ for 2 . The calculated average $\mathrm{Co}-\mathrm{N}$ distances for the corresponding $\mathrm{N}$-bound sulfonamide and O-bound sulfone structures are significantly longer at $2.17 \AA$ and $2.14 \AA$ A , respectively.

We then compared the reactivities of $\mathbf{2}$ and 2-Sc in hydrogen atom transfer (HAT) reactions from the hydrocarbon substrates xanthene, 9,10-dihydroanthracene (DHA), 1,4-cyclohexadiene (CHD), benzyl alcohol $\left(\mathrm{PhCH}_{2} \mathrm{OH}\right)$ and 1-benzyl-1,4dihydronicotinamide (BNAH). In all cases, addition of a substrate led to significantly accelerated decay of the chromophore associated with 2 and 2-Sc. In the presence of an excess substrate this proceeded with first-order kinetics and the resulting effective rate constants $\left(k_{\text {eff }}\right)$ were found to be linearly dependent upon substrate concentration, thereby yielding second-order rate constants. Such reaction kinetics are consistent with the direct reaction of 2 and 2-Sc with a substrate or alternatively a rapid pre-equilibrium yielding an alternative active oxidant. Intermediacy of a more traditional imidometal $\left[\left(\mathrm{TMG}_{3} \text { tren }\right) \mathrm{Co}^{\mathrm{IV}}-(\mathrm{NTs})\right]^{2+}$ oxidant would, therefore, require rapid reversible $\mathrm{N}-\mathrm{I}$ bond scission. Given that there is no precedence for this and the high energy calculated for the N-bound isomer, which would be a necessary intermediate in its formation, this seems highly improbable. As a consequence, we postulate that the O-bound sulphonamide isomer is the active oxidant.

Table 1 Substrate reactivity studies for 2 and 2-Sc

\begin{tabular}{|c|c|c|c|c|c|}
\hline \multirow[b]{2}{*}{ Substrate } & \multirow[b]{2}{*}{$\mathrm{BDE}_{\mathrm{C}-\mathrm{H}}\left(\mathrm{kcal} \mathrm{mol}^{-1}\right)$} & \multirow{2}{*}{\multicolumn{2}{|c|}{ Product $(\% \text { yield })^{a}$}} & \multicolumn{2}{|c|}{$k_{2}\left(10^{-2} \mathrm{M}^{-1} \mathrm{~s}^{-1}\right)$ at $-40^{\circ} \mathrm{C}$} \\
\hline & & & & 2 & 2-Sc \\
\hline BNAH & 67.6 & \multicolumn{2}{|c|}{ - } & 210.1 & 190.5 \\
\hline Xanthene & 74.0 & \multicolumn{2}{|c|}{-} & 2.06 & 1.14 \\
\hline CHD & 76.0 & \multicolumn{2}{|c|}{ Benzene (65) } & 1.32 & 1.38 \\
\hline DHA & 76.3 & \multicolumn{2}{|c|}{ Anthracene (60) } & 0.74 & 1.17 \\
\hline $\mathrm{PhCH}_{2} \mathrm{OH}$ & 80.0 & \multicolumn{2}{|c|}{ PhCHO (52) } & 0.20 & $0.37^{b}$ \\
\hline \multirow[t]{2}{*}{$\mathrm{Ph}_{3} \mathrm{P}$} & - & \multicolumn{2}{|c|}{$\mathrm{Ph}_{3} \mathrm{P}=\mathrm{NTs}(100)$} & 53.1 & 3.21 \\
\hline & & \multirow[b]{2}{*}{$\sigma$} & \multirow[b]{2}{*}{$\mathrm{p} K_{\mathrm{a}}$} & \multicolumn{2}{|c|}{$k_{2}\left(10^{-2} \mathrm{M}^{-1} \mathrm{~s}^{-1}\right)$ at $-20^{\circ} \mathrm{C}$} \\
\hline $\mathrm{X}$-DTBP $\mathrm{X}=$ & $\mathrm{BDE}_{\mathrm{O}-\mathrm{H}}\left(\mathrm{kcal} \mathrm{mol}^{-1}\right)$ & & & 2 & 2-Sc \\
\hline $\mathrm{MeO}$ & 78.3 & -0.78 & 14.82 & 100.8 & 208.7 \\
\hline $\mathrm{Me}$ & 81 & -0.31 & 14.77 & 2.42 & 0.70 \\
\hline${ }^{t} \mathrm{Bu}$ & 81.2 & -0.26 & 14.82 & 1.97 & 1.06 \\
\hline $\mathrm{H}$ & 82.1 & 0 & 14.22 & 0.43 & 0.05 \\
\hline $\mathrm{CHO}$ & 83.1 & 0.40 & 9.33 & 40.12 & 6.61 \\
\hline $\operatorname{MeC}(\mathrm{O})$ & 83.1 & 0.48 & 10.27 & 31.29 & 4.32 \\
\hline $\mathrm{COOH}$ & 83.4 & 0.55 & - & 63.47 & 2.84 \\
\hline $\mathrm{CN}$ & 84.2 & 0.66 & 10.15 & 35.82 & 2.67 \\
\hline
\end{tabular}

${ }^{a}$ Yields are for complex 2 and calculated based on the amount of the starting complex 1; yields for reactions with 2-Sc are comparable to 2 .

${ }^{b}$ The rate was determined using less than 150 equiv. of benzyl alcohol. 
Product analysis of the reaction mixtures of DHA, CHD and $\mathrm{PhCH}_{2} \mathrm{OH}$ reactions revealed the formation of the corresponding dehydrogenated products (Table 1) in 52-65\% yields;
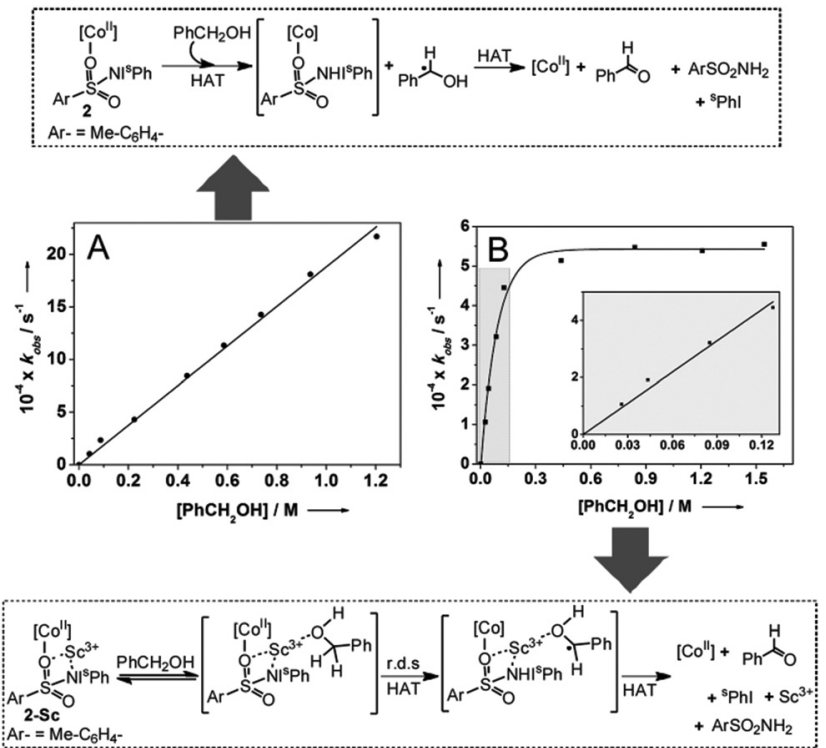

Fig. 3 Proposed mechanisms for hydrogen atom abstraction from benzyl alcohol based on the dependence of the $k_{\text {obs }}$ values of complexes 2 (A) and 2-Sc (B) at $-40{ }^{\circ} \mathrm{C}$ on the concentrations of benzyl alcohol. $\mathrm{B}$ inset: expansion of the highlighted region for low concentrations of $\mathrm{PhCH}_{2} \mathrm{OH}$. r.d.s = rate determining step; HAT = hydrogen atom transfer.

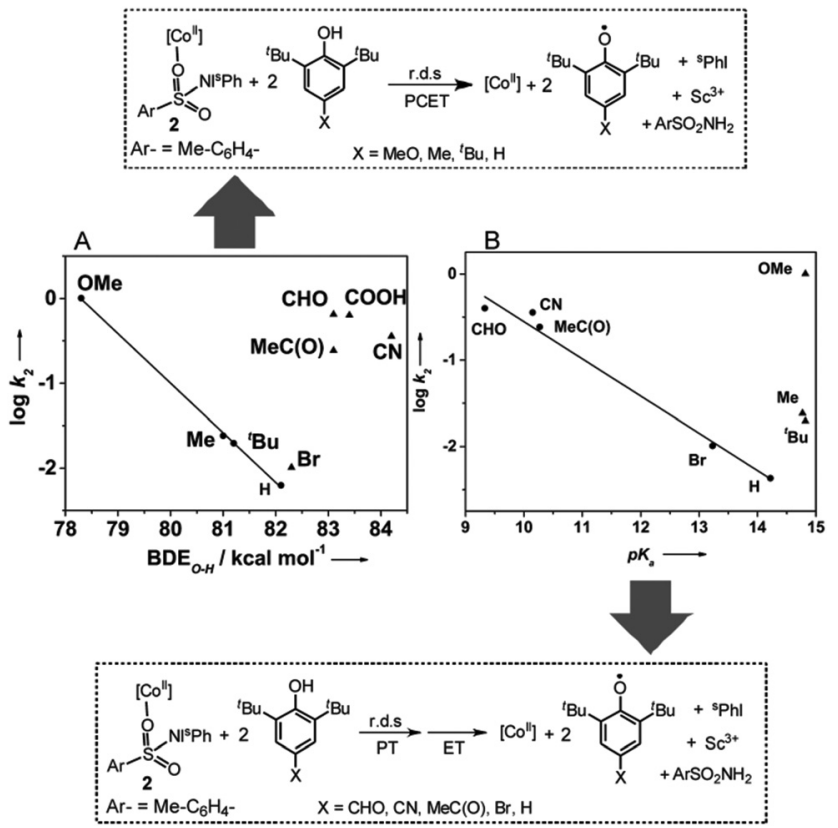

Fig. 4 Proposed mechanisms for the hydrogen atom transfer reactions from different substituted phenols based on the dependence of the $k_{\text {obs }}$ values of complex 2 on the $\mathrm{O}-\mathrm{H}$ bond dissociation energies (A), as well as, the $\mathrm{p} K_{\mathrm{a}}(\mathrm{B})$ of the phenols. $\mathrm{PCET}=$ proton coupled electron transfer; $\mathrm{PT}=$ proton transfer; $\mathrm{ET}=$ electron transfer; r.d.s = rate determining step. $p$-toluenesulfonamide $\left(\mathrm{ArSO}_{2} \mathrm{NH}_{2}\right.$; see Fig. 3 and 4$)$ is also detected as a reaction product ( $80-85 \%$ yield) in each case. Control reactions of the substrate with ${ }^{s}$ PhINTs alone or with ${ }^{\mathrm{s}} \mathrm{PhINTs}+\mathrm{Sc}^{3+}$ did not lead to any oxidation products. Thus, ${ }^{\mathrm{s}}$ PhINTs is activated upon binding to the $\left\{\left(\mathrm{TMG}_{3}\right.\right.$ tren $\left.) \mathrm{Co}^{\mathrm{II}}\right\}$ core. Interestingly, the second order rate constants $\left(k_{2}\right)$ determined at $-40{ }^{\circ} \mathrm{C}$ are comparable both in the absence and presence of $\mathrm{Sc}^{3+}$ ions (Table 1). This is in contrast to the previous report of the enhancement of the oxidizing capabilities of the corresponding metal-oxo intermediates ${ }^{6,8}$ in the presence of various Lewis-acids. Furthermore, the $k_{2}$ values form a linear correlation (Fig. S10 $\dagger$ ) with the $\mathrm{C}-\mathrm{H}$ bond dissociation energies $\left(\mathrm{BDE}_{\mathrm{C}-\mathrm{H}}\right)^{9}$ of the substrates, which indicates that $\mathrm{C}-\mathrm{H}$ bond homolysis is the rate determining step (r.d.s) in these reactions.

In order to obtain additional mechanistic insights, deuterium kinetic isotope effects (KIE) on the second-order rate constant $k_{2}(\mathrm{C}-\mathrm{H}) / k_{2}(\mathrm{C}-\mathrm{D})$ were measured for reactions of xanthene and DHA with 2. Values of 1.87 and 1.66 were determined at $-40{ }^{\circ} \mathrm{C}$ for xanthene and DHA (Fig. S11A and B $\dagger$ ), respectively, indicating that proton transfer is involved in the rate determining step. These KIE values are significantly smaller than those typically seen for high-valent metal-oxo and metal-imido mediated HAT reactions (3-25). ${ }^{1,2}$ This is again consistent with the $\left[\left(\mathrm{TMG}_{3} \text { tren }\right) \mathrm{Co}^{\mathrm{II}}-\left({ }^{\mathrm{s}} \mathrm{PhINTs}\right)\right]^{2+}$ core in 2 not evolving to a reactive high-valent $\left[\left(\mathrm{TMG}_{3} \text { tren }\right) \mathrm{Co}^{\mathrm{IV}}-(\mathrm{NTs})\right]^{2+}$ species prior to the reaction, and supports the suggestion that it is able to act directly as the reactive species in these oxygenation reactions.

Although the presence of $\mathrm{Sc}^{3+}$ did not significantly perturb the rate of $\mathrm{C}-\mathrm{H}$ bond homolysis mediated by the $\left[\left(\mathrm{TMG}_{3}\right.\right.$ tren $)$ $\left.\mathrm{Co}^{\mathrm{II}}-\left({ }^{\mathrm{S}} \mathrm{PhINTs}\right)\right]^{2+}$ core, it does affect a change in the mechanism in the reaction with $\mathrm{PhCH}_{2} \mathrm{OH}$. As expected, the addition of large excess of $\mathrm{PhCH}_{2} \mathrm{OH}$ (30-1000 equivalents) to preformed solutions of 2 at $-40{ }^{\circ} \mathrm{C}$ caused pseudo-first order decay (Fig. S12 $\dagger$ ) of the absorption bands associated with this complex at 420 and $820 \mathrm{~nm}$. Furthermore, the rate of decay was found to increase linearly with increasing $\mathrm{PhCH}_{2} \mathrm{OH}$ concentration (Fig. 3A), thereby affording a second order rate constant $\left(k_{2}\right)$ of $0.0020 \mathrm{M}^{-1} \mathrm{~s}^{-1}$. The pseudo-first order rate constants $\left(k_{\text {obs }}\right)$ for the reaction of 2-Sc with 30-150 equivalents of $\mathrm{PhCH}_{2} \mathrm{OH}$ were also observed to follow a linear correlation, and a second order rate constant $\left(k_{2}\right)$ of $0.0037 \mathrm{M}^{-1} \mathrm{~s}^{-1}$ at $-40{ }^{\circ} \mathrm{C}$ was measured (Table 1; Fig. 3B inset). However, at higher concentrations ( $>150$ equivalents) the correlation became non-linear with saturation behavior being obtained (Fig. 3B). The simplest model to account for these findings is to invoke the presence of a relatively fast equilibrium preceding the rate-determining step. ${ }^{10}$ More specifically, $\mathrm{PhCH}_{2} \mathrm{OH}$ reversibly binds to 2-Sc (Fig. 3) to yield a substrate bound intermediate $\left[\left(\mathrm{TMG}_{3}\right.\right.$ tren $\left.) \mathrm{Co}^{\mathrm{II}}-\left({ }^{\mathrm{S}} \mathrm{PhINTs}\right) \cdots \mathrm{Sc}^{3+} \ldots \mathrm{O}(\mathrm{H})-\mathrm{CH}_{2} \mathrm{Ph}\right]$, which then undergoes $\mathrm{C}-\mathrm{H}$ bond cleavage by a rate determining $\mathrm{H}$-atom abstraction process. At high $\mathrm{PhCH}_{2} \mathrm{OH}$ concentrations (>150 equivalents), the equilibrium shifts completely towards the substrate-bound species and the rate becomes independent of $\mathrm{PhCH}_{2} \mathrm{OH}$ concentration, thereby explaining the saturation kinetics. 
This notion is further reinforced by the absence of saturation kinetics for the other substrates, which do not possess a ligating atom, and 2, which lacks a Lewis acidic binding site.

Mechanistic studies for the reaction of 2 and 2-Sc with para-substituted 2,6-di-tert-butylphenols [X-DTBP; $\mathrm{X}=-\mathrm{OMe}$, $\left.-\mathrm{Me},-{ }^{t} \mathrm{Bu},-\mathrm{H},-\mathrm{CN},-\mathrm{CHO},-\mathrm{COOH},-\mathrm{MeC}(\mathrm{O})\right]$ reveal that the second-order rate constants depend markedly on the electrondonating/-withdrawing properties of the para-substituents (Table 1). For all the substituted phenols studied, second order kinetic behavior (Fig. S13†) and identical reaction products, namely $\mathrm{ArSO}_{2} \mathrm{NH}_{2}$ and two equivalents of the corresponding phenoxyl radical, were observed. However, when the rates obtained for both 2 and 2-Sc are plotted as a function of $\sigma$ of the para-substituents a linear correlation with a negative Hammett slope (Fig. S14†), as previously reported for the reaction of metal-oxo ${ }^{11 a}$ and -superoxo ${ }^{11 b}$ intermediates with phenol substrates, is obtained only for the electron-donating substituents $\left(\mathrm{X}=-\mathrm{OMe},-{ }^{t} \mathrm{Bu},-\mathrm{Me}\right.$, and $\left.-\mathrm{H}\right)$. The $k_{2}$ values for the electron withdrawing substituents $[\mathrm{X}=-\mathrm{CN},-\mathrm{CHO}$, $-\mathrm{COOH},-\mathrm{MeC}(\mathrm{O}),-\mathrm{Br}]$ appear significantly above the trend line, thereby hinting at a change in the mechanism for these substrates.

In response, we also plotted the rate constants against the O-H bond dissociation energy (BDE). ${ }^{9}$ Once again, a linear correlation with a negative slope comparable to that obtained for the metal-oxo and -dioxygen intermediates was observed for the phenols with electron-donating substituents, but the data for the phenols with electron-withdrawing groups appeared outside the correlation (Fig. 4A and S15A $\dagger$ ). Plotting $\log k_{2}$ versus $\mathrm{p}_{\mathrm{a}}{ }^{12}$ (Fig. $4 \mathrm{~B}$ and $\mathrm{S} 15 \mathrm{~B} \dagger$ ) revealed that for $\mathrm{X}$-DTBP with $\mathrm{X}=-\mathrm{CHO},-\mathrm{C}(\mathrm{O}) \mathrm{Me},-\mathrm{CN},-\mathrm{Br}$, and $-\mathrm{H}$, the rate $\left(\log k_{2}\right)$ decreased linearly with decreasing acidity (increasing $\mathrm{p} K_{\mathrm{a}}$ ), whereas the rates for the electron donating substituents $-\mathrm{MeO},-\mathrm{Me}$, and $-{ }^{t} \mathrm{Bu}$ scatter irregularly. From the above studies we can conclude that $\mathbf{2}$ and 2 -Sc oxidize acidic phenols (X-DTBP; $\mathrm{X}=-\mathrm{CN},-\mathrm{CHO},-\mathrm{COOH},-\mathrm{C}(\mathrm{O}) \mathrm{Me}$ ) via a stepwise proton transfer and electron transfer mechanism, with the proton transfer (PT) being effectively rate determining. This is likely to involve an initial proton transfer to solvent (acetone) to give a phenolate anion, which may bind to the $\mathrm{Co}$ (II) center and is much easier to oxidize than the phenol itself. The resulting rate acceleration, therefore, parallels the extent of ionization (acidity) of the phenol. In contrast, less acidic phenols like MeO-DTBP, Me-DTBP, and ${ }^{t} \mathrm{Bu}-\mathrm{DTBP}$, proceed via a concerted proton-coupled electron transfer (PCET) mechanism. Interestingly, data for 2,6-di-tert-butylphenol (H-DTBP) falls in all the plots of the second-order rate constant $\left(\log k_{2}\right)$ versus the thermochemical parameters $\mathrm{BDE}_{\mathrm{O}-\mathrm{H}}$ and $\mathrm{p} K_{\mathrm{a}}$ (Fig. 4A, B and S15A, B $\dagger$ ), thereby locating H-DTBP on the mechanistic borderline between the concerted PCET and stepwise PT-ET reaction pathways.

The reaction of excess triphenylphosphine (30-60 equivalents) with preformed 2 and 2 -Sc at $-40{ }^{\circ} \mathrm{C}$ leads to the quantitative formation of triphenylphosphonium tosylaza-ylide $\left(\mathrm{Ph}_{3} \mathrm{P}=\mathrm{NTs}\right)$ and regeneration of the starting $\mathrm{Co}^{\mathrm{II}}$ complex 1. Interestingly, the second order rate constants $\left(k_{2}\right)$ determined for the reactions of 2 and 2-Sc with $\mathrm{PPh}_{3}$ are 0.531 and $0.0321 \mathrm{M}^{-1} \mathrm{~s}^{-1}$, respectively, demonstrating that the group-transfer reactivity of 2 is decelerated by factors of $\sim 15$ upon binding of $\mathrm{Sc}^{3+}$ ions (Table 1; Fig. S16 and $\mathrm{S} 17 \dagger$ ).

\section{Conclusions}

In conclusion, we have provided spectroscopic evidence supporting formation of a metal-iminoiodane complex 2 and its scandium adduct 2-Sc. A novel binding mode of ${ }^{5}$ PhINTs via the sulfonamide O-atom is predicted in 2 based on DFT calculations. Both 2 and 2-Sc possess cobalt in a +2 oxidation state. This is in sharp contrast to the analogous oxo chemistry, ${ }^{6}$ where the presence of scandium led to the stabilization of an unusual $\left\{\mathrm{Co}^{\mathrm{IV}}-\mathrm{O}-\mathrm{Sc}^{3+}\right\}$ core. The formation of the isoelectronic $\left\{\mathrm{Co}^{\mathrm{IV}}-\mathrm{N}(\mathrm{Ts})-\mathrm{Sc}^{3+}\right\}$ core in 2 -Sc, which would require a short Co-N(Ts) distance, is presumably prevented by the additional steric demands of the tosyl group, which is absent in the oxo chemistry. The reaction of 2 and 2-Sc with 4-substituted 2,6-ditert-butylphenols is shown to proceed via a stepwise PT-ET mechanism for electron withdrawing substituents. Although PT-ET mechanisms have previously been invoked for the oxidation of phenols by organic radicals, ${ }^{13}$ this is the first experimental evidence for a metal complex mediated variant. Additionally, the presence of $\mathrm{Sc}^{3+}$ in 2-Sc is shown to promote the formation of a precursor complex during the oxidation of benzyl alcohol, thereby demonstrating the cooperativity of two metal centers in promoting substrate oxidation reactions. Taken together, the present study expands our understanding of metal-mediated oxidation reactions using iminoiodanes, with metal-iminoiodane adducts being demonstrated to be a second plausible oxidant, in addition to the often invoked high-valent metal-imido reactive intermediates, ${ }^{2 b, c, e}$ in hydrogen atom abstraction and group transfer reactions.

We gratefully acknowledge financial support of this work from the Cluster of Excellence "Unifying Concepts in Catalysis" (EXC 314/2), Berlin. K. R. also thanks the Heisenberg-Programm of the Deutsche Forschungsgemeinschaft for financial support. W. N. acknowledges financial support from the NRF of Korea through the CRI (NRF-2012R1A3A2048842) and GRL (NRF-2010-00353). JE is thankful to the NAP fellowship of the Nanyang Technological University.

\section{Notes and references}

1 (a) D. Ostovic and T. C. Bruice, Acc. Chem. Res., 1992, 25, 314; (b) M. Costas, Coord. Chem. Rev., 2011, 255, 2912; (c) R. T. Gephart and T. H. Warren, Organometallics, 2012, 31, 7728.

2 (a) W. Nam, Acc. Chem. Res., 2007, 40, 522; (b) J. Hohenberger, K. Ray and K. Meyer, Nat. Commun., 2012, 3, 720; (c) K. Ray, F. Heims and F. F. Pfaff, Eur. J. Inorg. Chem., 2013, 3784; (d) V. Lyaskovskyy, A. I. O. Suarez, H. Lu, H. Jiang, X. P. Zhang and B. de 
Bruin, J. Am. Chem. Soc., 2011, 133, 12264; (e) J. F. Berry, Dalton Trans., 2012, 41, 700.

3 (a) J. A. Smegal, B. C. Schardt and C. L. Hill, J. Am. Chem. Soc., 1983, 105, 3510; (b) S. H. Wang, B. S. Mandimutsira, R. Todd, B. Ramdhanie, J. P. Fox and D. P. Goldberg, J. Am. Chem. Soc., 2004, 126, 18; (c) W. Nam, S. K. Choi, M. H. Lim, J. Rohde, I. Kim, J. Kim, C. Kim and L. Que, Angew. Chem., Int. Ed., 2003, 42, 109; (d) A. Lennartson and C. J. McKenzie, Angew. Chem., Int. Ed., 2012, 124, 6871; (e) C. Wang, T. Kurahashi and H. Fujii, Angew. Chem., Int. Ed., 2012, 51, 7809; (f) C. Wang, T. Kurahashi, K. Inomata, M. Hada and H. Fujii, Inorg. Chem., 2013, 52, 9557; (g) B. Wang, Y.-M. Lee, M. S. Seo and W. Nam, Angew. Chem. Int. Ed., 2015, 54, 11740; (h) S. Hong, B. Wang, M. S. Seo, Y.-M. Lee, M. J. Kim, H. R. Kim, T. Ogura, R. Garcia-Serres, M. Clmancey, J.-M. Latour and W. Nam, Angew. Chem. Int. Ed., 2014, 53, 6388.

4 (a) M. J. Zdilla and M. M. Abu-Omar, J. Am. Chem. Soc., 2006, 128, 16971; (b) Z. Ke and T. R. Cundari, Organometallics, 2010, 29, 821.

5 (a) D. Macikenas, E. Skrzypczak-jankun and J. D. Protasiewicz, J. Am. Chem. Soc., 1999, 121, 7164; (b) S. Kundu, E. Miceli, E. Farquhar, F. F. Pfaff, U. Kuhlmann, P. Hildebrandt, B. Braun, C. Greco and K. Ray, J. Am. Chem. Soc., 2012, 134, 14710.
6 F. F. Pfaff, S. Kundu, M. Risch, S. Pandian, F. Heims, I. Pryjomska-Ray, P. Haack, R. Metzinger, E. Bill, H. Dau, P. Comba and K. Ray, Angew. Chem., Int. Ed., 2011, 50, 1711.

7 Owing to the structural complexity of 2-Sc, the actual binding site of scandium is not clear at present.

8 (a) J. Chen, Y.-M. Lee, K. M. Davis, X. Wu, M. S. Seo, K.-B. Cho, H. Yoon, Y. J. Park, S. Fukuzumi, Y. N. Pushkar and W. Nam, J. Am. Chem. Soc., 2013, 135, 6388; (b) S. Fukuzumi, Coord. Chem. Rev., 2013, 257, 1564.

9 Y.-R. Luo, Comprehensive handbook of chemical bond energies, Taylor \& Francis, 2007.

10 (a) I. Garcia-Bosch, A. Company, C. W. Cady, S. Styring, W. R. Browne, X. Ribas and M. Costas, Angew. Chem., Int. Ed., 2011, 50, 5648; (b) J. M. Mayer, Acc. Chem. Res., 2011, 44, 36.

11 (a) D. E. Lansky and D. P. Goldberg, Inorg. Chem., 2006, 45, 5119; (b) J. Cho, J. Woo, J. Eun Han, M. Kubo, T. Ogura and W. Nam, Chem. Sci., 2011, 2, 2057.

12 L. A. Cohen and W. M. Jones, J. Am. Chem. Soc., 1963, 81, 3397.

13 (a) G. Litwinienko and K. U. Ingold, J. Org. Chem., 2003, 68, 3433; (b) G. Litwinienko and K. U. Ingold, J. Org. Chem., 2004, 69, 5888; (c) M. C. Foti, C. Daquino and C. Geraci, J. Org. Chem., 2004, 69, 2309. 